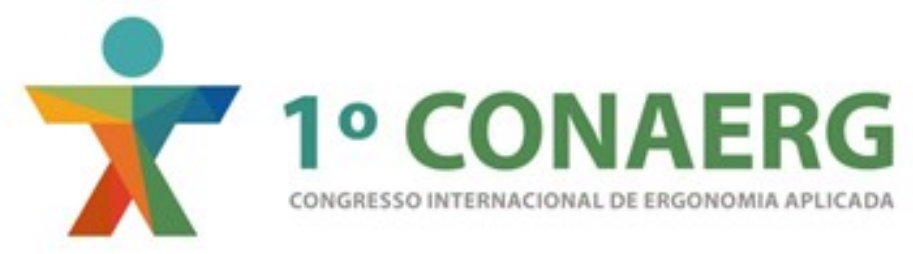

\title{
AVALIAÇÃO DE USABILIDADE PARA COMPUTADORES PORTÁTEIS: UMA ANÁLISE COMPARATIVA ENTRE O MACKBOOK PRO 13 COM TELA DE RETINA E O NOTEBOOK DELL ISPIRON 14
} 3000.

\author{
Simone Jacqueline Portela Simão (1); \\ Marilande Andrade (2); \\ Marcelo Gomes (3); \\ Waldelourdes de Melo Souto Maior (4); \\ Marcelo Márcio Soares (5)
}

Universidade Federal de Pernambuco,

(1) (2) (3) (4) Mestrandos em Ergonomia

(1) e-mail:simone jacqueline@yahoo.com.br

(2) e-mail: marilande_andrade@hotmail.com

(3) e-mail: marceloh2@yahoo.com.br

(4) e-mail: walmelosoutomaior@gmail.com

(5) PhD em Ergonomia

e-mail: soaresmm@gmail.com

\begin{abstract}
RESUMO
O presente artigo refere-se a um estudo de usabilidade para computadores portáteis onde fizemos a análise comparativa entre o Mackbook Pro 13 tela de Retina e o Notebook Dell Ispiron 14 3000. Para saber a opinião do usuário foram aplicados questionários e entrevistas. Para fundamentar este estudo aplicamos a etapa de apreciação do sistema homem-tarefa-máquina (Moraes e Mont'Alvão (2000); e para delinearmos as características do design associadas a usabilidade dos produtos foi feita uma análise de acordo com os princípios de usabilidade de Jordan (1998). Ao final do artigo são apresentados os resultados obtidos no estudo e sugestões de melhorias.
\end{abstract}

Palavras-chave: Usabilidade, Interação humano-tarefa-máquina e Ergonomia. 
This article refers to a usability study for laptops where we made a comparative analysis between the Mackbook Pro 13 Retina display and the Dell Notebook Ispiron 14 3000. To know the user opinion, surveys and interviews were applied. To support this study apply the step of assessing the humantask machine system (Moraes and Mont'Alvão, 2000); and to outline the design characteristics associated with usability of the products, we made an analysis in accordance with the principles of usability Jordan (1998). At the end of the article, the results obtained in the study and suggestions for improvements are presented.

Keywords: Usability, Interaction human-task machine and Ergonomics.

\section{INTRODUÇÃO}

O avanço da tecnologia permitiu o surgimento de novas concepções de computadores pessoais e com isso surgiram os laptops, os primeiros computadores pessoais portáteis, com dispositivo de entrada e saída muito semelhantes ao computador de mesa, que graças a sua mobilidade têm sido uma opção bastante procurada entre os consumidores.

Jordan (2000) afirma que, para se atingir um público consumidor, é necessário atender a três requisitos: entender os consumidores, saber o que querem e dar a eles o que querem.

Hoje se sabe que a qualidade do desempenho do usuário está ligada à qualidade de sua interface com o sistema. Assim, interface pode ser conceituada como parte do sistema com o qual o usuário realiza contato através do plano físico, perceptivo e cognitivo. Maddix, 1990 (apud BARROS, 2003).

Neste sentido, Veldof, Prasse e Mills (1999) apontam os testes de usabilidade como sendo uma ótima forma de se entender o que os usuários querem e de que precisam para realização de suas tarefas.

A usabilidade pode ser compreendida como a capacidade, em termos funcionais humanos, de um sistema ser usado facilmente e com eficiência pelo usuário. (SANTOS, 2000)

Dentro desse contexto o objetivo deste trabalho foi fazer uma Avaliação de Usabilidade para Computadores Portáteis: Uma Análise Comparativa entre o Mackbook Pro $13 \mathrm{com}$ tela de Retina e o Notebook Dell Ispiron 143000.

\subsection{Apresentação do Produto}

\subsubsection{Macbook Pro 13 com Tela de Retina}

É um equipamento voltado para entretenimento multimídia e para aplicações profissionais, como design gráfico, manipulação de imagens de alta resolução e edição profissional de vídeo. Mas pode ser usado no dia a dia para rodar vídeos, conferir fotos, navegar nas redes sociais e organizar uma grande coleção de músicas. Podemos observá-lo na figura 1.

Figura 1 - Imagens do Macbook Pro 13 (Fonte: www.apple.com/br).
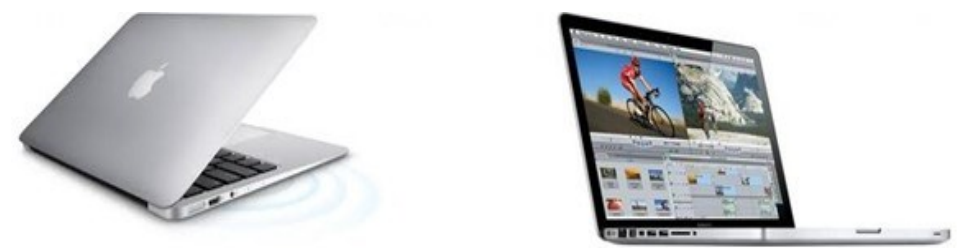


\subsubsection{Notebook Dell Ispiron 143000}

O design do Notebook Dell Ispiron 143000 é bem simples com linhas retas. O acabamento é texturizado, mas todo em plástico. Não é recomendado para quem busca jogar em alta qualidade e trabalhar com programas de edição de imagens e vídeo. Podemos observá-lo na figura 2.

Figura 2 - Imagens do Dell Ispiron 143000

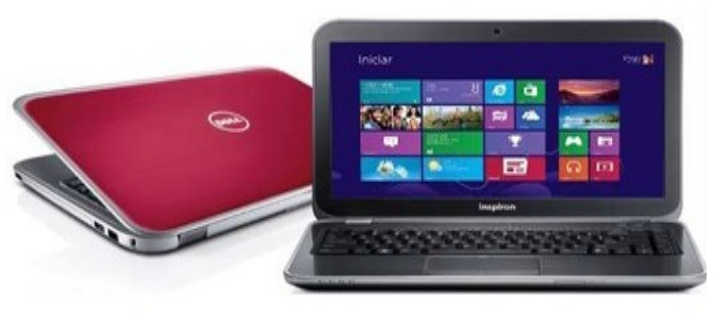

Fonte: www.dell.com/br

\subsubsection{Especificações do Macbook Pro 13 e do Notebook Dell Ispiron 143000}

As especificações dos dois produtos podem ser observadas abaixo na figura 3. Onde podemos verificar as semelhanças e/ou diferenças entre os equipamentos.

Figura 3 - Apresentação das especificações do Macbook Pro 13 e do Notebook Dell.

\begin{tabular}{|c|c|c|}
\hline Especificações do Produto & MacBook Pro 13 & Notebook Inspiron 14 \\
\hline Sistema operacional & OS X El capitan & Modelo Linux Ubuntu ou Windows \\
\hline Tela do monitor & $\begin{array}{l}\text { Tela de retina } 13,3 \text { polegadas retroiluminada por LED, } \\
\text { com tecnologia IPS, resolução de } 2560 \times 1600 \text {. }\end{array}$ & $\begin{array}{l}\text { Tela de } 14 \text { polegadas resolução } 1366 \times 768 \text { LED } \\
\text { Backlit Display com Truelife. } 14 \text { polegadas, } \\
\text { resolução } 1.366 \times 768 \text {. }\end{array}$ \\
\hline Processador & $\begin{array}{l}\text { 2,7GHz Processador Intel Core i5 dual core de } 2,7 \mathrm{GHz} \\
\text { (Turbo Boost de até } 3,1 \mathrm{GHz} \text { ) com } 3 \mathrm{MB} \text { de cache } \mathrm{L} 3 \\
\text { compartilhado }\end{array}$ & $\begin{array}{l}\text { Processador Intel@ Core }{ }^{\mathrm{TM}} \text { i3 } 5^{\mathrm{a}} \text { Geração i3- } \\
5005 \mathrm{U} \text {.Velocidade } 2.0 \mathrm{GHz} \text {. Barramento (FSB) } \\
5 \mathrm{GT} / \mathrm{s} \text {. Memória Cache 3M. }\end{array}$ \\
\hline Memória & 4 GB de memória DDR3, $1600 \mathrm{MHz}$ & 4 GB de memória DDR3L. 16GB. \\
\hline Armazenamento & $\begin{array}{l}\text { 512GB Armazenamento baseado em flash PCle de } \\
\text { 512GB, Possibilidade de configuração para 1TB de } \\
\text { armazenamento flash. }\end{array}$ & $\begin{array}{l}\text { Interface SATA } 6 \text { Gbps, HD: uma unidade de } \\
2,5 \text { ". Unidade óptica: Uma unidade de DVD+/- } \\
\text { RW de } 9,5 \text { mm, Capacidade } 1 \text { TB Velocidade } \\
\text { de rotação HD } 5400 \text { RPM. }\end{array}$ \\
\hline $\begin{array}{l}\text { Conexões e } \\
\text { Expansão }\end{array}$ & $\begin{array}{l}\text { Porta de alimentação MagSafe } 2 \\
\text { Duas portas Thunderbolt } 2 \text { (de até } 20 \mathrm{Gbps} \text { ). Duas } \\
\text { portas USB } 3 \text { (de até } 5 \mathrm{Gbps} \text { ). Porta HDMI c/Conector } \\
\text { de fone de ouvido de } 3,5 \mathrm{~mm} \text {. Slot para cartão SDXC }\end{array}$ & $\begin{array}{l}\text { Conector RJ45 USB, Porta USB 3.0. Duas } \\
\text { portas USB } 2.0 \text { áudio/vídeo, Porta HDMI } \\
\text { Porta p/fones de ouvido e microfone (headset). } \\
\text { Slot p/meio minicartão p/Wifi e Bluetooth }\end{array}$ \\
\hline Teclado e touchpad & $\begin{array}{l}\text { Teclado padrão retroiluminado com } 78 \text { (EUA) ou } 79 \\
\text { (ISO) teclas, } 12 \text { teclas de função e } 4 \text { teclas de direção } \\
\text { Touchpad Force touch p/controle preciso do cursor } \\
\text { e sensores de pressão. Possibilita toques fortes. }\end{array}$ & $\begin{array}{l}\text { Teclado resistente a derramamento de líquidos } \\
\text { em padrão ABNT } \\
\text { Touchped multito que ativado por gestos com } \\
\text { rolagem integrada e eletrostático. }\end{array}$ \\
\hline $\begin{array}{l}\text { Bateria e } \\
\text { Energia }\end{array}$ & $\begin{array}{l}\text { Até } 10 \mathrm{hrs} \text { de } \mathrm{p} / \text { wireless na web e } 12 \text { p/reprodução de } \\
\text { vídeos do iTunes. Até } 30 \text { dias p/modo de espera. } \\
\text { Bateria de polímero de lítio incluída c/consumo de } 74,9 \\
\text { watts/hora. }\end{array}$ & $\begin{array}{l}\text { Bateria recarregável bivolt, de } 4 \text { células, } 40 \\
\text { WHr e com duração de até } 8 \text { horas }\end{array}$ \\
\hline Wireless & $\begin{array}{l}\text { Wi-Fi } 802.11 \mathrm{n}^{3} \mathrm{c} / \text { rede wireless compatível com IEEE } \\
802.11 \mathrm{a} / \mathrm{b} / \mathrm{g} \\
\text { Bluetooth } 4.0\end{array}$ & Dell Wireless-N 170 \\
\hline Suporte a gráficos e vídeo & $\begin{array}{l}\text { Intel Iris graphics } 6100 \text {. Saída de vídeo thunderbolt e } \\
\text { HDMI. Saída mini displayport nativa. }\end{array}$ & $\begin{array}{l}\text { Tipo: Integrada } \\
\text { Modelo Intel } ₫ \text { HD Graphics } 4400 \\
\text { Conexões: HDMI1.4 } \\
1 \text { x USB } 3.0 ; 2 \text { x USB 2.0;1 RJ-45 }\end{array}$ \\
\hline Câmera & Câmera FaceTime HD de 720p & Webcan com 1 megapíxel HD \\
\hline
\end{tabular}


O presente trabalho para fazer a análise comparativa de usabilidade entre o Mackbook Pro 13 e o Notebook Dell Ispiron 143000 fez uso de uma pesquisa de cunho exploratório descritiva quanti-qualitativa.

Segundo Leite (2007), a avaliação de usabilidade pode ser realizada levando em consideração diferentes métodos, que podem ser definidos de acordo com o objetivo da avaliação.

Assim sendo, durante a avaliação verificamos as características dos produtos (de acordo com os dados e diretrizes para o projeto de produtos). Aplicamos a etapa de apreciação do sistema homem-tarefa-máquina (Moraes e Mont'Alvão, 2000) - a representação esquemática das interações entre os elementos de um sistema homem-tarefa-máquina; o fluxograma funcional ação-decisão representativo dos equipamentos avaliados durante o experimento, onde apresentamos a análise da tarefa de ligar e desligar os equipamentos.

Para avaliar as possíveis insatisfações e desconfortos, caracterizar o perfil do usuário e ainda levantar opiniões e sugestões desses usuários em relação aos produtos estudados foi realizado uma entrevista informal e aplicado um questionário com perguntas fechadas e abertas.

Na sequência foi feito ainda, a Avaliação de Interfaces do Usuário e do Produto com as Interfaces Físicas. Moran,1981, diz que a interface de usuário deve ser entendida como sendo a parte de um sistema computacional com a qual uma pessoa entra em contato física, perceptiva ou conceitualmente.

Depois delineamos as características do design associadas a usabilidade dos produtos de acordo com os princípios de usabilidade de Jordan (1998). Esses princípios traçam como cada item pode afetar a usabilidade em uma interface.

Jordan (1998), ainda sugere princípios que delineiam como cada um deles pode afetar a usabilidade em uma interface. São eles: consistência, compatibilidade, capacidade, retroalimentação, prevenção ou correção de erros, controle do usuário, clareza visual, priorização da funcionalidade e da informação, transferência adequada de tecnologia e evidência. A especificação das exigências baseadas nos princípios de usabilidade colabora para a concepção de um produto centrado no usuário e no conforto de seu uso. (apud SILVA at al, 2015)

$\mathrm{Na}$ etapa final do estudo foi feita a avaliação e análise dos resultados e foram apontadas sugestões de melhorias e apresentadas às conclusões.

\section{AVALIAÇÃO DO PRODUTO}

\subsection{Dados e diretrizes para o projeto de produtos}


Nesta etapa foram verificadas as características físicas dos produtos. Tanto o Macbook Pro 13 quanto o Notebook Dell Ispiron 14 3000, são classificados como produtos portáteis. São equipamentos que o usuário pode carregar tranquilamente por vários minutos sem cansar.

Os dados e as diretrizes para o projeto de produtos portáteis e transportáveis são baseados no peso e tamanho do produto, fatores esses que afetam a sua portabilidade. De acordo com nossa analise avaliativa o Macbook Pro 13 foi considerado o menor e com menor peso. Sendo por essa razão o produto mais fácil de ser transportado. Como podemos observar na figura 4.

Figura 4 - Quadro comparativo de peso e tamanho dos equipamentos.

\begin{tabular}{|l|l|l|}
\hline \multicolumn{1}{|c|}{ Peso e Tamanho } & \multicolumn{1}{c|}{ Macbook Pro 13 } & \multicolumn{1}{c|}{ Notebook Dell Ispiron 14 } \\
\hline Peso & $1,58 \mathrm{~kg}(3,48 \text { libras })^{2}$ & $2,11 \mathrm{~kg}(4,65$ libras $)$ \\
\hline Altura & $1,8 \mathrm{~cm}(0,71$ polegada $)$ & $2,66 \mathrm{~cm}(1,04$ polegadas $)$ \\
\hline Largura & $31,4 \mathrm{~cm}(12,35$ polegadas $)$ & $34,6 \mathrm{~cm}(13,62$ polegadas $)$ \\
\hline Espessura & $21,9 \mathrm{~cm}(8,62$ polegadas $)$ & $24,6 \mathrm{~cm}(9,68$ polegadas $)$ \\
\hline
\end{tabular}

\subsection{Modelo do Sistema Homem-Tarefa-Máquina}

Existe uma relação recíproca entre o ser humano e a máquina, como pode ser observada na figura 5. O modelo apresentado é igual para o Macbook pro 13 e para o Notebook Dell Ispiron 143000.

Figura 5 - Representação esquemática das interações entre os elementos de um sistema homem-tarefa-máquina.

\section{Modelo do Sistema Humano-Tarefa-Máquina}

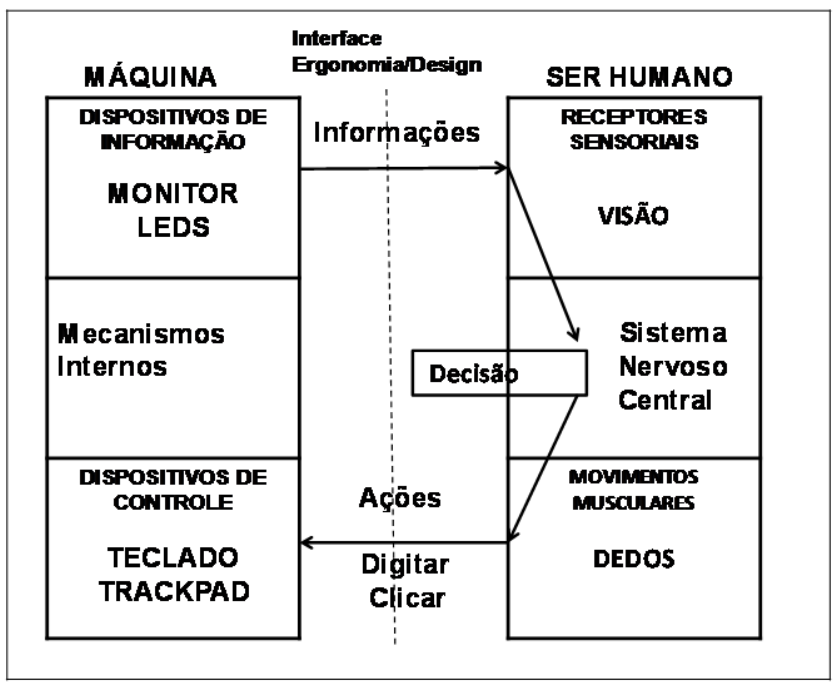

Moraes e Mont'Alvão, 2000

\subsection{Fluxograma Funcional Ação-Decisão - Análise da tarefa}


Neste fluxograma fizemos a análise da tarefa de ligar e desligar os equipamentos. Durante observações podemos verificar que os procedimentos são iguais para o Macbook Pro 13 e para o Notebook Dell ispire 143000 . O que esta representado na figura 6.

Figura 6 - Fluxograma funcional Ação-Decisão representativo dos dois equipamentos avaliados durante o experimento.

\section{Análise da Tarefa \\ Ligar e desligar o Computador Portátil}

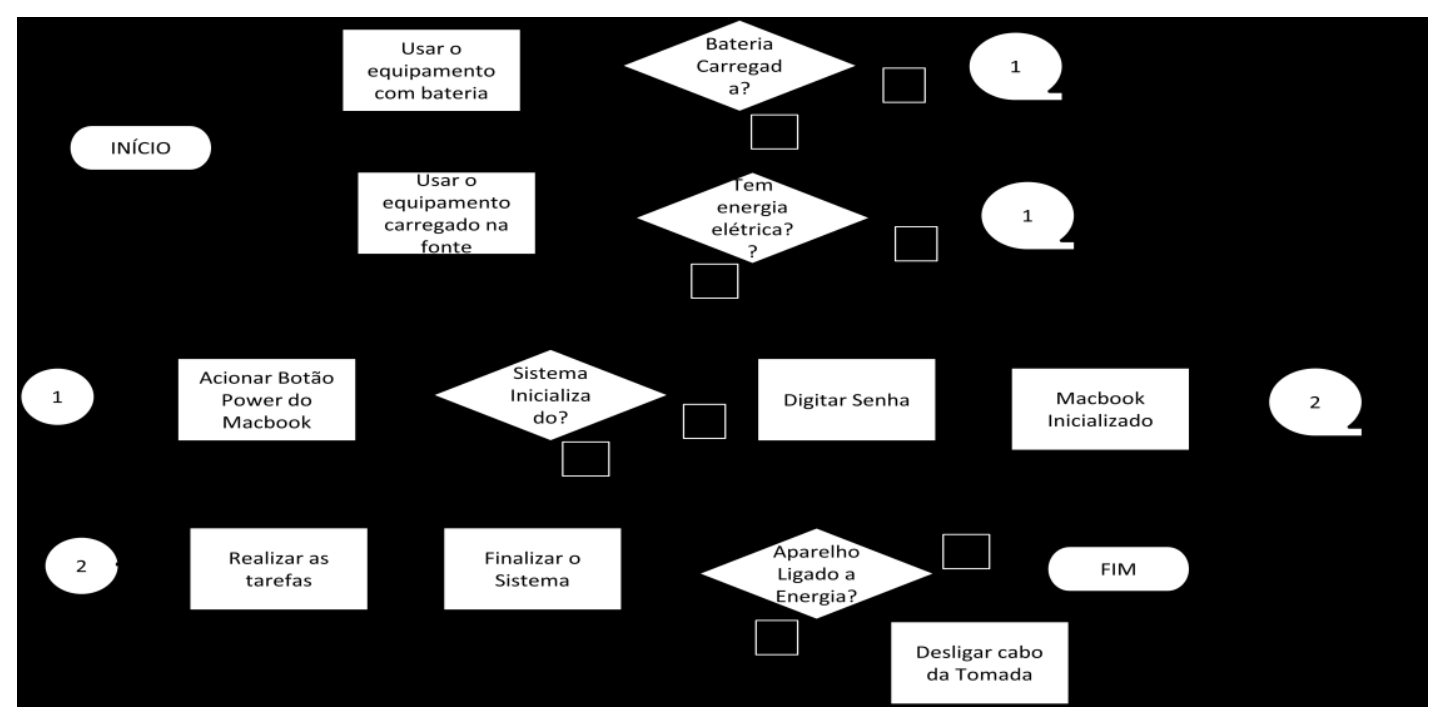

\subsection{Avaliação de Interfaces do Usuário e do Produto com as Interfaces Físicas}

Tanto no Notebook quanto no Macbook essa interação é feita:

- Manipulação de elementos visuais:

○ É baseada em janelas, e;

○ Formulários de preenchimento (digitação de senha).

- Manipulação e combinação:

- Interação multimodal - As informações para o sistema são fornecidas pelos usuários através do teclado.

\subsection{Delimitação do problema}

Nesta etapa fizemos a seleção e classificação dos vários aspectos da situação do problema por meio da Análise de Disfunção da interface produto-usuário. Durante a fase da problematização de acordo com os dados levantados durante a pesquisa podemos verificar que os equipamentos estudados, não apresentam grandes problemas e são bem aceitos pelos usuários.

\subsubsection{Disfunções da Máquina - Notebook Pro 13}


A borda afiada do descanso para mãos em frente ao touchpad podem machucar os usuários.

Os produtos Apple de uma maneira geral apresentam problemas de falta de flexibilidade no uso de acessórios. O que acaba encarecendo ainda mais seus produtos.

\section{- $\quad$ Problemas da má performance dos componentes e subsistemas}

Existe uma falha de reconhecimento de disco no DVD que impede de montar DVDs que as vezes mesmo com a substituição do Drive, o problema as vezes se repete.

A webcam HD integrada segundo alguns usuários tem desempenho considerado mediano para as chamadas de vídeo.

Aquecimento excessivo quando usa alguns aplicativos mais pesados.

- $\quad$ Problemas de solidez, confiabilidade, padronização e fabricação

Existe uma falha no gabinete alguns proprietários têm reclamado que após alguns meses de uso aparecem rachaduras e quebras no invólucro plástico dos portáteis, no descanso para pulsos, abaixo do teclado, nos cantos da traseira do computador e nos respiros.

\subsubsection{Disfunções da Máquina - Notebook Dell Ispiron 143000.}

\section{- $\quad$ Problemas da má performance dos componentes e sub-sistemas}

O touchpad eletrostático deixa a desejar, para alguns usuários poderia ser mais sensível ao toque. Um dos usuários afirmou só conseguir trabalhar com uso de um mouse. E ainda um deles mencionou que a falta de botões físicos atrapalha no desempenho do trabalho.

Desempenho modesto e tela fraca, muito reflexiva e com ângulos de visão limitados, usuários disseram haver percebido distorções nas cores e imagens com apenas mexer um pouco a cabeça para a direita ou esquerda.

\section{- Problemas sócio-culturais e semiológico}

Aparência externa e interna do equipamento foi considerada pouco atrativa. Um dos usuários afirmou que é muito quadrado. Um fato que chamou atenção dos participantes é que o equipamento é todo feito em plástico texturizado e disseram esperar que a Dell usasse materiais mais nobres,

\subsubsection{Tabela de Formulação de Problema (TFP)}

Nesta etapa evidenciamos os aspectos mais significativos e solúveis dos problemas que foram requeridos pelo usuário e a empresa. Na figura 7 podemos observar a TFP para o Note Book Pro 13 e na figura 8 a TFP para o Notebook Dell 13.

Figura 7 - Tabela de Formulação de Problema - Notebook Pro 13. 


\begin{tabular}{|c|c|c|c|c|c|}
\hline $\begin{array}{l}\text { Problemas } \\
\text { estruturais e de } \\
\text { movimento }\end{array}$ & \begin{tabular}{lr}
\multicolumn{2}{l}{ - A borda viva do } \\
descanso & para \\
punhos. & \\
$-\quad$ Falta & de \\
flexibilidade & no \\
uso & de \\
acessórios &
\end{tabular} & $\begin{array}{l}\text { - Machuca mão e } \\
\text { punhos } \\
\text {-Encarece o } \\
\text { produto }\end{array}$ & $\begin{array}{l}\text { - Retarda o } \\
\text { trabalho }\end{array}$ & $\begin{array}{l}\text { - Colocar bordas } \\
\text { arrendondadas } \\
\text { - Rever } \\
\text { planejamento da } \\
\text { empresa quanto } \\
\text { a flexibilização }\end{array}$ & $\begin{array}{l}\text { - Desinteresse da } \\
\text { empresa } \\
\text { - Desinteresse da } \\
\text { empresa }\end{array}$ \\
\hline $\begin{array}{l}\text { Problemas da } \\
\text { má performance } \\
\text { dos } \\
\text { componentes e } \\
\text { sub-sistemas }\end{array}$ & $\begin{array}{ll}\text { - Falha no drive } \\
\text { de DVD } & \\
-\quad \text { Webcam cl } \\
\text { baixo } & \\
\text { desempenho } & \\
\text { para } & \text { as } \\
\text { chamadas de } & \text { vídeo } \\
\text { - Aquecimento } & \end{array}$ & $\begin{array}{l}\text { - Insatisfação } \\
\text { - Insatisfação } \\
\text { - Insatisfação e } \\
\text { estresse }\end{array}$ & $\begin{array}{l}\text { - Impossibilita o } \\
\text { trabalho } \\
\text { - Distorção de } \\
\text { imagens } \\
\text { - Impossibilita o } \\
\text { trabalho }\end{array}$ & $\begin{array}{l}\text { - Providenciar } \\
\text { outro tipo de } \\
\text { drive } \\
\text { - Colocar } \\
\text { webcam de } \\
\text { melhor } \\
\text { desempenho } \\
\text { - Melhorar } \\
\text { sistema de } \\
\text { resfriamento }\end{array}$ & $\begin{array}{l}\text { - Desinteresse da } \\
\text { empresa } \\
\text { - Desinteresse da } \\
\text { empresa } \\
\\
\text { - Desinteresse da } \\
\text { empresa }\end{array}$ \\
\hline $\begin{array}{l}\text { Problemas de } \\
\text { solidez, } \\
\text { confiabilidade, } \\
\text { padronização e } \\
\text { fabricação }\end{array}$ & $\begin{array}{l}\text { - Rachaduras e } \\
\text { quebras }\end{array}$ & $\begin{array}{l}\text { - Insatisfação e } \\
\text { estresse }\end{array}$ & $\begin{array}{l}\text { - Impossibilita o } \\
\text { uso do produto. }\end{array}$ & $\begin{array}{l}\text { - Usar um } \\
\text { material mais } \\
\text { resistente }\end{array}$ & $\begin{array}{l}\text { - Desinteresse da } \\
\text { empresa }\end{array}$ \\
\hline
\end{tabular}

Figura 8 - Tabela de Formulação de Problema - Notebook Dell Ispiron 143000.

\begin{tabular}{|c|c|c|c|c|c|c|}
\hline $\begin{array}{l}\text { Classe de } \\
\text { Problema }\end{array}$ & Problemas & $\begin{array}{l}\text { Requerimentos } \\
\text { do Design }\end{array}$ & $\begin{array}{l}\text { Problemas } \\
\text { Humanos }\end{array}$ & $\begin{array}{c}\text { Custos } \\
\text { Humanos do } \\
\text { Trabalho }\end{array}$ & Sugestões & $\begin{array}{l}\text { Limitações do } \\
\text { Sistema }\end{array}$ \\
\hline $\begin{array}{l}\text { Problemas da } \\
\text { má performance } \\
\text { dos } \\
\text { componentes e } \\
\text { sub-sistemas }\end{array}$ & $\begin{array}{l}\text { - O touchpad } \\
\text { pouco sensível } \\
\text { ao toque e falta } \\
\text { de botões físicos } \\
\text { - Tela fraca, } \\
\text { muito reflexiva }\end{array}$ & & $\begin{array}{l}\text { - Insatisfação e } \\
\text { estresse } \\
\text { - Cansaço visual }\end{array}$ & $\begin{array}{l}\text { - Dificulta o } \\
\text { trabalho } \\
\text { - Dificulta a } \\
\text { visão/retarda o } \\
\text { trabalho }\end{array}$ & $\begin{array}{l}\text { - Melhorar o } \\
\text { projeto do } \\
\text { touchpad } \\
\text { - Melhorar a tela }\end{array}$ & $\begin{array}{l}\text { - Desinteresse da } \\
\text { empresa } \\
\text { - Desinteresse da } \\
\text { empresa }\end{array}$ \\
\hline $\begin{array}{l}\text { Problemas } \\
\text { sócio-culturais e } \\
\text { semiológico }\end{array}$ & $\begin{array}{l}\text { - Aparência } \\
\text { externa e interna } \\
\text { do equipamento } \\
\text { foi considerada } \\
\text { pouco atrativa }\end{array}$ & $\begin{array}{l}\text { - Planejar um } \\
\text { design mais } \\
\text { bonito e agradável }\end{array}$ & - Insatisfação & & $\begin{array}{l}\text { - Melhorar o } \\
\text { design }\end{array}$ & $\begin{array}{l}\text { - Desinteresse da } \\
\text { empresa }\end{array}$ \\
\hline
\end{tabular}

\section{AVALIAÇÃO DE USABILIDADE MACKBOOK PRO 13 COM TELA DE RETINA E DO NOTEBOOK DELL ISPIRON 143000 - PONTO DE VISTA DO USUÁRIO}

Para a análise da avaliação dos produtos estudados sob o ponto de vista do usuário fizemos uso de entrevistas informais e aplicamos um questionário com perguntas abertas e fechadas. Este estudo teve como objetivo avaliar o comportamento do usuário em relação a: 1) Facilidade de uso dos produtos; 2) Se o usuário gostaria de utilizar o equipamento com frequência; 3) Se o equipamento é desnecessariamente complexo; 4) Se precisaria de ajuda para utilizar o equipamento; 5) Se as várias funções do equipamento estão bem integradas; 6) Se há muita inconsistência neste equipamento; 7) Se acha que a maioria das pessoas aprenderia a usar este equipamento rapidamente; 8) este equipamento muito incômodo de usar; 9) Eu me senti muito seguro(a) utilizando este equipamento; e, 10) Precisei aprender muitas coisas antes de utilizar este equipamento.

\subsection{Perfil do usuário}


A entrevista foi feita com seis usuários sendo: dois do sexo feminino e quatro do sexo masculino com idades entre 21 e 30 anos. Todos com experiência no uso de computadores e todos proprietários de computadores portáteis (dois proprietários de notebooks marca DELL, dois de Macbooks Pro 13 e dois de notebooks de outras marcas). O perfil desses usuários pode ser facilmente verificado na figura 9.

\section{Figura 9 - Quadro de Perfil dos usuários}

Quadro de Perfil dos Usuários

\begin{tabular}{|c|c|c|c|c|c|c|}
\hline Perguntas & Usuário (1) & Usuário (2) & Usuário (3) & Usuário (4) & Usuário (5) & Usuário (6) \\
\hline Idade & 21 anos & 22 Anos & 23 anos & 27 anos & 27 anos & 26 anos \\
\hline Sexo & Masculino & Feminino & Masculino & Feminino & Masculino & Masculino \\
\hline $\begin{array}{l}\text { Profissão e } \\
\text { escolaridade }\end{array}$ & $\begin{array}{l}\text { Estudante Sistema de } \\
\text { Informação }\end{array}$ & $\begin{array}{l}\text { Estudante de } \\
\text { Administração }\end{array}$ & Militar & Administradora & $\begin{array}{l}\text { Funcionário } \\
\text { Público }\end{array}$ & $\begin{array}{l}\text { Designer } \\
\text { Industrial }\end{array}$ \\
\hline $\begin{array}{l}\text { Tempo você } \\
\text { utiliza um } \\
\text { computador? }\end{array}$ & Mais de 5 anos & Mais de 5 anos & $\begin{array}{l}\text { Mais de } 5 \\
\text { anos }\end{array}$ & Mais de 5 anos & $\begin{array}{l}\text { Mais de } 5 \\
\text { anos }\end{array}$ & Mais de 5 anos \\
\hline $\begin{array}{l}\text { Quantas horas } \\
\text { por semana } \\
\text { você utiliza o } \\
\text { computador? }\end{array}$ & Mais de $10 \mathrm{~h}$ & Entre 5 e $10 \mathrm{~h}$ & $\begin{array}{l}\text { Mais de } 10 \\
\text { horas }\end{array}$ & Mais de 10 horas & $\begin{array}{l}\text { Mais de } 10 \\
\text { horas }\end{array}$ & $\begin{array}{l}\text { Entre } 5 \text { e } 10 \\
\text { horas }\end{array}$ \\
\hline $\begin{array}{l}\text { Você tem } \\
\text { notebook? }\end{array}$ & Sim & Sim & Sim & Sim & Sim & Sim \\
\hline $\begin{array}{l}\text { Há quanto } \\
\text { tempo você é } \\
\text { usuário de } \\
\text { notebook? }\end{array}$ & De 3 a 5 anos & Mais de 5 anos & $\begin{array}{l}\text { Mais de } 5 \\
\text { anos }\end{array}$ & De 1 a 3 anos & $\begin{array}{l}\text { De } 1 \text { a } 3 \\
\text { anos }\end{array}$ & Mais de 5 anos \\
\hline
\end{tabular}

\subsection{Opinião dos Usuários - Macbook Pro 13 com tela de retina}

Os resultados obtidos na pesquisa podem ser visualizados na figura 10 abaixo.

Figura 10 - Quadro de opiniões dos usuários Macbook Pro 13.

\begin{tabular}{|l|l|}
\multicolumn{2}{|c|}{ Questões } \\
\hline É fácil de usar & Três usuários concordam e três concordam completamente. \\
\hline Gostaria de usar com frequência & Três usuários concordam e três concordam completamente. \\
\hline Equipamento é complexo & Seis usuários discordam completamente \\
\hline Precisaria de ajuda para usá-lo & $\begin{array}{l}\text { Dois usuários discordam e quatro discordam completamente desta } \\
\text { afirmação. }\end{array}$ \\
\hline As funções no equipamento estão bem integradas & Um usuário é neutro e cinco concordam. \\
\hline Há inconsistências no equipamento & Dois usuários são neutros e quatro discordam. \\
\hline $\begin{array}{l}\text { A maioria das pessoas aprenderiam a usá-lo } \\
\text { rapidamente }\end{array}$ & Os seis usuários concordaram. \\
\hline Equipamento é incomodo ao usar & Dois usuários discordam completamente, três discordam e um é neutro \\
\hline $\begin{array}{l}\text { Senti seguro a utilizá-lo } \\
\text { É necessário aprender muitas coisas antes de } \\
\text { usá-lo }\end{array}$ & Cinco usuários concordam e um concorda completamente. \\
\hline
\end{tabular}

\subsection{Opinião dos Usuários - Notebook Dell Ispiron 143000}

Podemos observar os resultados na pesquisa na figura 11 abaixo.

Figura 11 - Quadro de opiniões dos usuários Notebook Dell Ispiron 143000.

\begin{tabular}{|l|l|}
\hline \multicolumn{1}{|c|}{ Questões } & \multicolumn{2}{c|}{ Opiniões dos Usuários } \\
\hline É fácil de usar & Três usuários concordam e três concordam completamente. \\
\hline Gostaria de usar com frequência & Um discorda completamente, um discorda, Três concordam e um \\
\hline
\end{tabular}




\begin{tabular}{|l|l|}
\hline \multicolumn{1}{|c|}{ concorda completamente. } \\
\hline Equipamento é complexo & Três usuários discordam completamente, dois discordam e um concorda \\
\hline Precisaria de ajuda para usá-lo & $\begin{array}{l}\text { Três usuários discordam e três discordam completamente desta } \\
\text { afirmação }\end{array}$ \\
\hline As funções no equipamento estão bem integradas & $\begin{array}{l}\text { Um usuário discorda um é neutro dois concordam e dois concordam } \\
\text { completamente }\end{array}$ \\
\hline Há inconsistências no equipamento & Um discorda completamente, quatro discordam e um foi neutro \\
\hline $\begin{array}{l}\text { A maioria das pessoas aprenderiam a usá-lo } \\
\text { rapidamente }\end{array}$ & Dois foram neutros, três concordam e um concorda completamente \\
\hline Equipamento é incomodo ao usar & Três discordam completamente, dois discordam e um concorda \\
\hline $\begin{array}{l}\text { Senti seguro a utilizá-lo } \\
\text { ú necessário aprender muitas coisas antes de }\end{array}$ & Dois foram neutros, dois concordam e dois concordam completamente \\
\hline
\end{tabular}

\section{AVALIAÇÃO SEGUNDO AS RECOMENDAÇÕES DE USABILIDADE DE JORDAN}

Nesta etapa foram delineadas as características do design associadas a usabilidade do Macbook Pro 13 e do Notebook Dell Ispiron 14, de acordo com os princípios de usabilidade de Jordan (1998). Eles traçam como cada item pode afetar a usabilidade em uma interface. A especificação das exigências baseadas nos princípios de usabilidade colabora para uma concepção de produto centrado no usuário e no conforto de seu uso.

A seguir, a figura 12 apresenta os resultados do diagnóstico dos pesquisadores que foram organizados de acordo com cada uma das dez orientações de usabilidade de Jordan (1998).

Figura 12 - resultado da avaliação segundo os dez princípios de usabilidade de Jordan (1998).

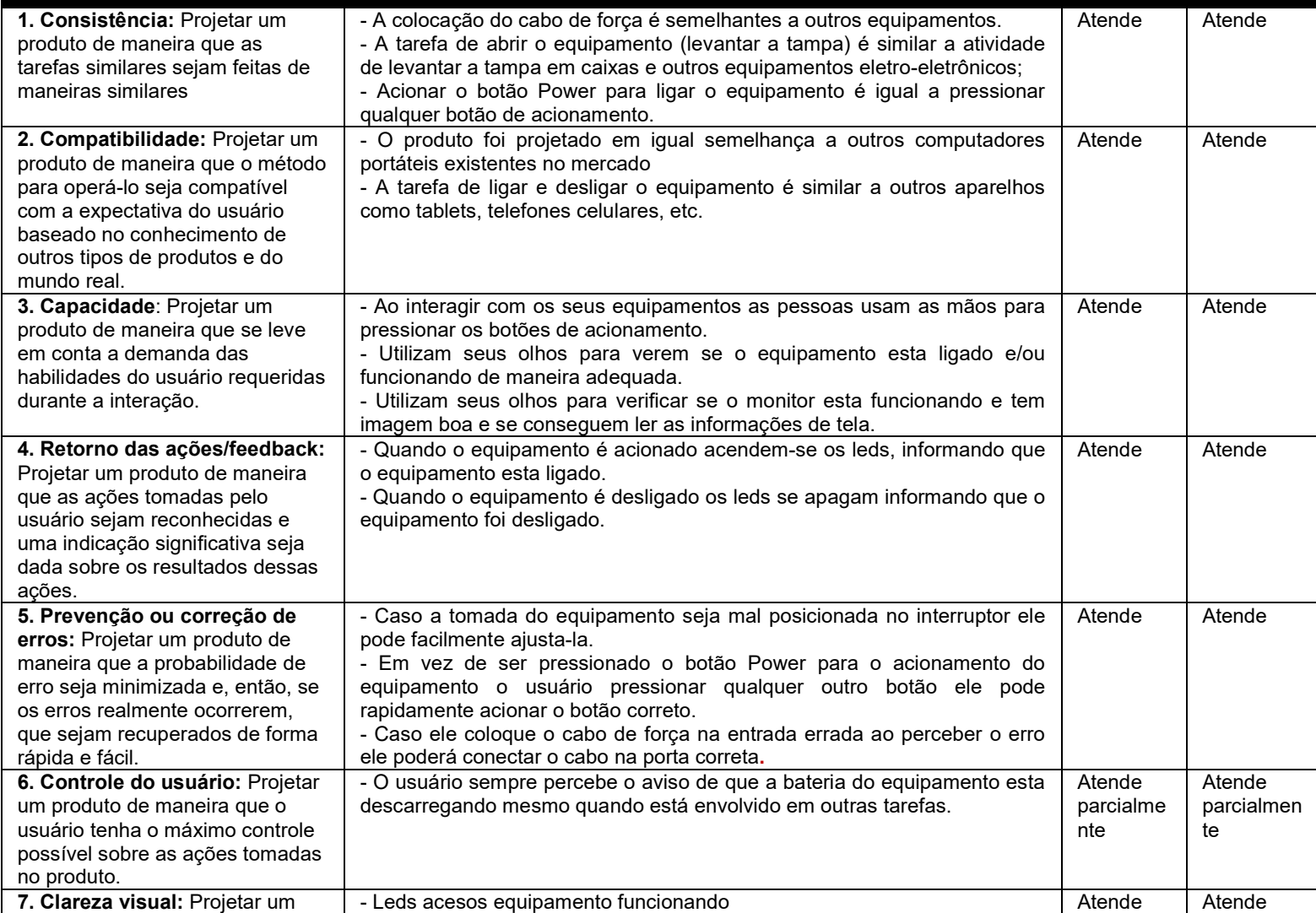




\begin{tabular}{|c|c|c|c|}
\hline $\begin{array}{l}\text { produto de maneira que a } \\
\text { informação apresentada seja lida } \\
\text { de forma rápida e fácil, sem } \\
\text { causar confusão. }\end{array}$ & $\begin{array}{l}\text { - Leds apagados equipamento desligado. } \\
\text { - Luz da bateria acesa, informa que a bateria esta ligada na tomada. }\end{array}$ & & \\
\hline $\begin{array}{l}\text { 8. Priorização da } \\
\text { funcionalidade e da } \\
\text { informação: Projetar um produto } \\
\text { de maneira que a funcionalidade } \\
\text { e a informação mais importantes } \\
\text { sejam facilmente acessadas pelo } \\
\text { usuário. }\end{array}$ & $\begin{array}{l}\text { - Recursos visuais são utilizados para informações de ações realizadas } \\
\text { pelos usuários. } \\
\text { Os botões de acionamento do equipamento ficam em uma área separada } \\
\text { do trackpad } \\
\text { As entradas USB, para cabos são localizadas na parte lateral do } \\
\text { equipamento. }\end{array}$ & Atende & Atende \\
\hline $\begin{array}{l}\text { 9. Transferência adequada de } \\
\text { tecnologia: Projetar um produto } \\
\text { de maneira que se faça uso } \\
\text { adequado de tecnologias } \\
\text { desenvolvidas para outros } \\
\text { contextos para aumentar a } \\
\text { usabilidade do produto. }\end{array}$ & $\begin{array}{l}\text { - Tecnologia das telecomunicações aproveitadas para trocas de } \\
\text { mensagens faladas através de microfone, webcam e sons do } \\
\text { equipamento. } \\
\text { - Tecnologia criada para aparelhos de DVD e de equipamentos de som } \\
\text { foram transferidas para os equipamentos para através de seu monitor e } \\
\text { uso de placas de vídeos e sons os usuários podem assitir vídeos e ouvir } \\
\text { musica. }\end{array}$ & Atende & Atende \\
\hline $\begin{array}{l}\text { 10. Evidência: a solução formal } \\
\text { do produto deve indicar } \\
\text { claramente a sua função e o } \\
\text { modo de operação. }\end{array}$ & $\begin{array}{l}\text { - Usar os mesmos termos das atividades executadas em um sistema, para } \\
\text { tarefas iguais no sistema; } \\
\text { - Ter analogias com outros equipamentos de conhecimento de usuários } \\
\text { intermediários. } \\
\text { - Comandos auto-explicativos, por meio de caixas de diálogo (quando o } \\
\text { equipamento emite uma caixa de texto solicitando a senha para iniciar o } \\
\text { equipamento, o usuário entende rapidamente a solicitação) }\end{array}$ & Atende & Atende \\
\hline
\end{tabular}

Fonte: Elaborada pelo autor com base na pesquisa realizada.

De acordo com a avaliação baseada nos dez princípios de usabilidade de Jordan (1998). Os produtos atenderam a nove desses princípios e em apenas um principio, o controle do usuário, foi considerado de atendimento parcial, uma vez que os usuários solicitaram uma mensagem mais clara para algumas chamadas dos equipamentos. Porém consideramos que esse item é de gravidade pequena, pois não afeta muito o desempenho dos equipamentos.

\section{SUGESTÕES DE MELHORIAS}

Considerando as opiniões dos usuários a partir da análise comparativa realizada verificou-se que os resultados foram semelhantes para os dois equipamentos, sendo que o Macbook Pro 13 foi o mais bem avaliado durante todo o estudo, levando vantagem sobre o Notebook Dell em todos os aspectos. Apenas um dos participantes não compraria o Notebook Dell Ispiron 14 3000. E todos mencionaram que gostariam de possuir um Macbook Pro 13 por seu desempenho superior, mas encontram uma barreira no item preço.

A Apple para melhorar o seu produto deveria colocar bordas arredondas no seu descanso para punhos, providenciar a instalação de outro tipo de drive de DVD que permita mais facilmente o reconhecimento de discos de reprodução de mídias, Instalar uma webcam com melhor qualidade de imagem, melhorar o sistema de resfriamento o que facilitaria o trabalho de pessoas que o utilizam com programas mais pesados e ainda deveria rever sua política de flexibilização de acessórios e aplicativos para facilitar a vida de seus clientes. Um dos participantes mencionou que a Apple poderia criar uma linha mais popular, mas desde que não baixasse muito o padrão de qualidade dos equipamentos.

A Dell para melhorar o seu equipamento deveria rever todo o projeto de seu produto, seu design deveria ser modificado para satisfazer as necessidades dos seus clientes, 0 touchpad é um ponto critico, pois foi mencionado pelos usuários como pouco sensível o que as vezes retarda muito sua utilização então deveria ser melhorado, a tela do equipamento também deixa a desejar por ser muito reflexiva e com ângulos de visão um pouco limitado 
então deveria ser trocada por outro tipo de tela que não seja tão reflexiva e que dê uma melhor qualidade de imagem. Os proprietários do Dell também mencionaram que o preço desse equipamento é caro comparado aos benefícios porque sua performance ficou muito abaixo de suas expectativas.

\section{CONCLUSÕES}

Durante a análise tivemos a oportunidade de conhecer detalhadamente os equipamentos e um pouco da opinião dos usuários quanto a utilização dos produtos estudados. Podemos perceber que os usuários do Macbook Pro são mais exigentes quanto a qualidade e especificações de seus equipamentos por terem níveis de exigências maiores em relação aos seus trabalhos. E que os dois equipamentos foram projetados para uso em distintas situações, porém podendo ser utilizado em qualquer situação decidida pelo proprietário desde que seja pertinente a utilização de um computador portátil a tarefa.

Podemos verificar que apesar dos usuários terem feito avaliações positivas ao Notebook Dell Ispiron 143000 também verificamos alguns comentários desaprovadores em relação ao produto. $\mathrm{O}$ que nos leva a crer que seria necessário um estudo mais aprofundado sobre $\mathrm{o}$ assunto.

Diante do acima mencionado, esperamos que as sugestões apontadas no artigo possam contribuir para melhoraria dos equipamentos. E que esse estudo abra caminhos para outras pesquisas nesse campo, pois é uma área rica em problemáticas a serem tratadas.

\section{REFERÊNCIAS BIBLIOGRÁFICAS}

BARROS, V. T. O. Avaliação da Interface de um Aplicativo Computacional através de Teste de Usabilidade, Questionário Ergonômico e Análise Gráfica do Design, 2003. Dissertação de mestrado. Programa de Pós-Graduação em Engenharia de Produção da Universidade Federal de Santa Catarina.

GRANDJEAN , E.; KROEMER, K. H. E. Manual de Ergonomia: Adaptando o Trabalho ao Homem. 5. ed. Porto Alegre: Bookman. 2005.

JORDAN, P. W. An Introduction to Usability. Londres: Taylor \& Francis Ltda., 1998.

JORDAN, P. W. Designing Pleasurable Products: An Introduction to the New Human Factors. 2000.

LEITE, K. A. A. Avaliação de usabilidade nos sistemas computacionais dos serviços de telemedicina do Bhtelessaúde. 2007. 132 f. Dissertação (Mestrado em Informática), Universidade Católica de Minas Gerais, Belo Horizonte. Disponível em: <http://www.biblioteca.pucminas.br/teses/Informatica_LeiteKA_1.pdf>. Acesso em: 29 jun. 2016.

MORAES, A.; MONT'ALVÃO, C.Ergonomia: conceitos e aplicações. 2. ed. Rio de Janeiro. 2AB, 2000

Moran, T. (1981) "The Command Language Grammars: a representation for the user interface of interactive computer systems. Em International Journal of Man-Machine Studies 15:3-50, Academic Press. 
SANTOS, R.L.G. Ergonomização da interação homem-computador: Abordagem heurística para avaliação de interfaces. Rio de Janeiro. 2000. 184p. Dissertação (Mestrado em Design) Departamento de Artes e Design, Pontifícia Universidade Católica do Rio de Janeiro.

SILVA, C. S at al.; Medidas e Princípios de usabilidade para a Concepção de um produto Voltado à Gestão de Design. Disponivel em <http://revistaergodesign-hci.dad.puc rio.br/media/4CarinaSILVA_EugenioMERINO_GiselleMERINO_LuizFIGUEIREDO\%20CompletoPO T.pdf.> Acesso em 30 jun 2016.

VELDOF, J. R.; PRASSE, M. J.; MILLS, V, A.; Chauffered by the user: usability in the eletronic library. Journal of Library Administration, v. 26, n. 3/4, p. 115-140, 1999. 